\title{
Optical properties and effects on direct solar irradiance of aerosols: Asian East case
}

\author{
Abdelmoula Ben-tayeb*, Mohammed Diouri, Abdelouahid Tahiri, and Rajae Meziane \\ Department of Physics, University of Mohammed First Faculty of science, Oujda, Morocco
}

\begin{abstract}
Atmospheric aerosol is an important factor that affects solar irradiance. In this study, we examined the total atmospheric optical depth, aerosol optical depth AOD and the vertical particle size distribution in East Asia in terms of aerosol type during three years. The temporal variation of the aerosol optical depth for each site showed a constant mode renewed each year, the large $\mathrm{AOD}_{0,5}$ are recorded in spring and summer in an almost periodic manner, with maximums around 0.95 in Seoul, 0.08 in Chiang Mai and 1.34 in EPA-NCU. The particle size distributions under a bimodal lognormal form present a remarkable increase in volume concentration of fine and coarse modes during spring. The aerosols reduce solar irradiance by $37.33 \pm 0.78 \%$ in Chiang Mai, $33.48 \pm 6.43 \%$ in EPA-NCU and $38.59 \pm 3.86 \%$ in Seoul.
\end{abstract}

\section{Introduction}

The satellite measurements of total solar radiation estimate the solar constant at $1361 \mathrm{~W} / \mathrm{m}^{2}$, which represents the average value of total solar radiation over a period of 42 years [1]. During penetration through the atmosphere, solar radiation is modified by interactions with atmospheric particles (molecules, aerosol and clouds). The solar spectrum curve varies according to the different absorption and scattering mechanisms with the particles [2]. The use of the optical properties of atmospheric components allows the determination of the attenuation of solar radiation where aerosols contribute significantly [3]. In Korea, PM2.5 and PM10 particles reduce solar PV by more than $10 \%$ of the maximum capacity under normal air quality conditions, while they reduce more than $20 \%$ of the maximum capacity under bad air quality [4].

Aerosols are particles suspended in the atmosphere they are present mainly in the troposphere and very few in the stratosphere and upper layers of the atmosphere, aerosols can be produced directly in the atmosphere like desert aerosols [5, 6] or formed by the conversion of gases. The aerosols have an important role in the atmosphere, as they are affected by climatic conditions and affect the climate with a direct way through the scattering and absorption of solar radiation [7 - 9]. And with an indirect way at the level of cloud formation process, the aerosols form the Cloud Condensation Nuclei, and thus the properties of clouds are related to the optical properties of the aerosols $[10,11]$.

In East Asia aerosols has a very complex spatiotemporal change in characteristics and optical properties [12]. There are different types of aerosol origins, such as biomass combustion, urban pollutant and mineral dust according to the seasons. The seasonal and monthly series of aerosol optical depth showed maximum in spring due to dust advections affected by polluted aerosols and minimum in autumn and winter [13]. Mineral dust particles come from the arid region of India during April and May [14]. Greenhouse gases, ozone and the direct effect of aerosols contribute to the trend of surface cooling [15].

\section{Site description, measurements and data}

AERONET is an international network of ground measurements and studies of the aerosol optical properties by the Sun photometers that provide measurements in the range 1060-340 with good accuracy and within every 15 minutes. In this study, we exploited the aerosol optical depth AOD and the total optical depth of the atmosphere to determine the attenuation of solar radiation by aerosols and by the atmosphere. We also analyses the particle size distributions, inversion products of the equations of the aerosols optical depth [16, 17]. Tab. 1 shows the characteristics of AERONET sites used in this study.

Car traffic emissions, mixed residential, industrial emissions and human activities affect regularly the air of Chiang Mai site (Indochina) [19]. AOD peaks in spring due to weather conditions and proximity to sources of biomass burning, these local factors influence the aerosol properties in the area [20]. A polluted continental urban environment characterizes also Seoul in the northern part of South Korea that imply a large temporal variation of the AODs [21]. In Taiwan, the optical properties of aerosols measured at a low-altitude site are characterized by the presence of abundant coarse particles due to the effect of dust from the Gobi Desert, in a high mountain site, the aerosol optical depths were mainly composed of fine particles. Diagnosis of aerosols at high altitudes

*orresponding author: abdelmoulabentayeb@gmail.com 
showed the presence of aerosols from combustion biomass transported from Southeast Asia and no dust [22].

Figure 1 represents the monthly average of AOD at the three sites over a three-year period, seasonal a rise appears almost periodically during each year with varying values. In Chiang Mai, the AOD rises during spring and may exceed 1.6 due to aerosols produced by the biomass combustions, and remains at 0.4 during the other periods of the year. The AOD in EPA-NCU records important values that may rise to 1.2 during spring and summer. At Seoul, the diversity of natural and industrial aerosol sources, explains is the important irregular change in the AODs, with an increase from early spring to the end of summer.

The particle size distribution gives an idea of the origin of the aerosols. All Sites present two lognormal modes, fine and coarse particles (Fig.2). In Chiang Mai and EPA-NCU, the fine mode predominates especially in spring that show the importance of the aerosols of biomass combustions, while fine and coarse modes seem more equivalent in Seoul.

\section{Attenuation of solar irradiance}

The solar irradiance on the earth surface is related to constant parameters, the latitude, the solar deviation, the solar constant and the angle of sunrise and sunset. In addition, variable parameters related to weather and climatic conditions play a key role. Aerosol extinctions, molecular scattering and gaseous absorption, attenuate solar radiations.

We developed a calculation program based on Iqbal formulations [23] to calculate the solar radiation on the earth surface without the influence of the atmosphere TA. We included after, the aerosol optical depth AOD and the total atmospheric optical depth in the calculation program to determine the attenuation of solar radiation by aerosols $\mathrm{AE}$ and by the total atmospheric components TE.

Table 1. AERONET Site characteristics [18]

\begin{tabular}{lccccc}
\hline Country & AERONET & Latitude & Longitude & Altitude $(\mathrm{m})$ & Study period \\
\hline Thailand & Chiang_Mai_Met_Sta & $18.77^{\circ} \mathrm{N}$ & $98.97^{\circ} \mathrm{E}$ & 312.0 & $2017-2019$ \\
Taiwan & EPA-NCU & $24.96^{\circ} \mathrm{N}$ & $121.18^{\circ} \mathrm{E}$ & 144.0 & $2017-2019$ \\
\multirow{2}{*}{ Korea } & Seoul SNU & $37.45^{\circ} \mathrm{N}$ & $126.95^{\circ} \mathrm{E}$ & 116.0 & $2016-2018$ \\
\hline
\end{tabular}
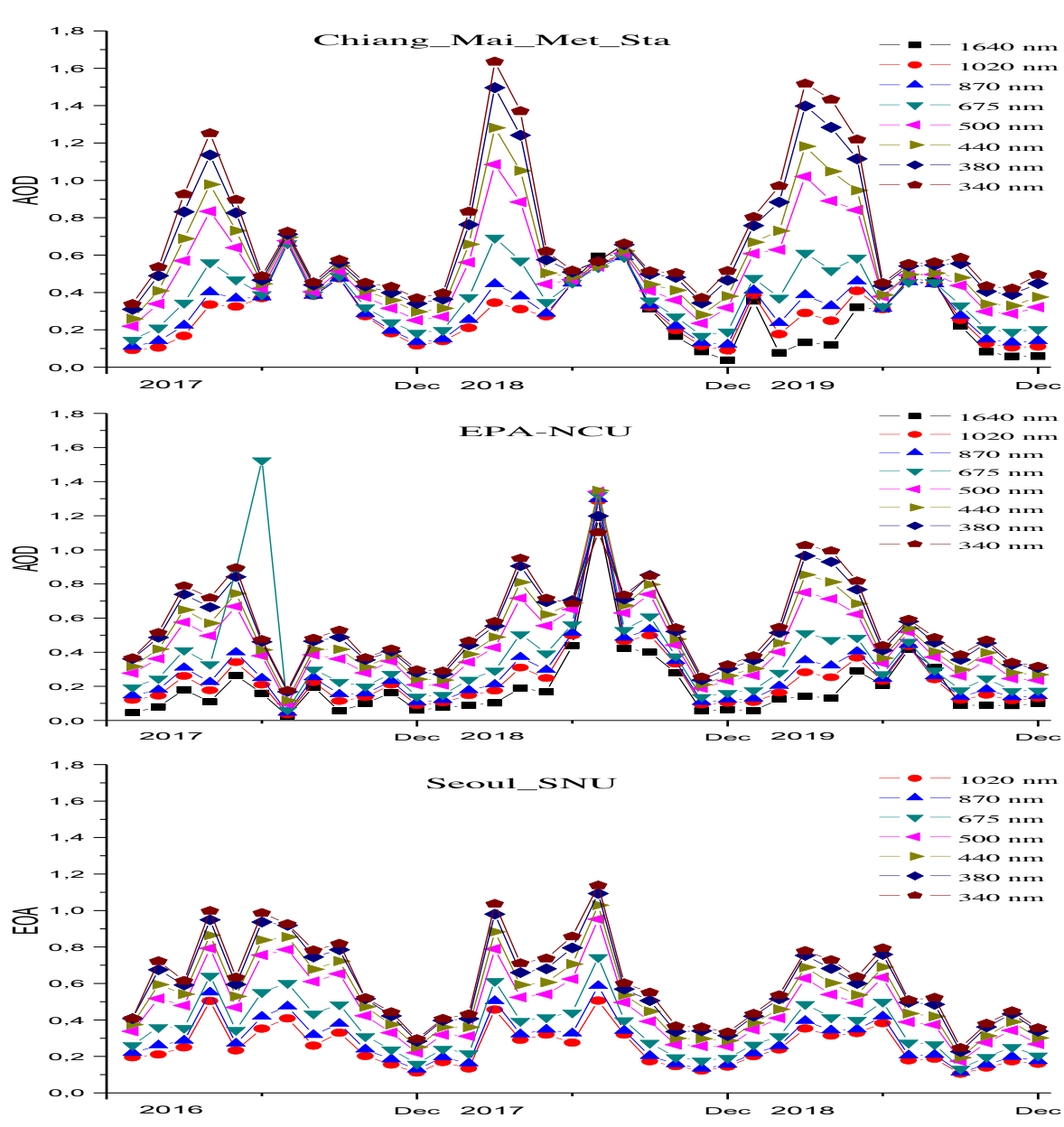

Fig. 1. Monthly AOD averages 


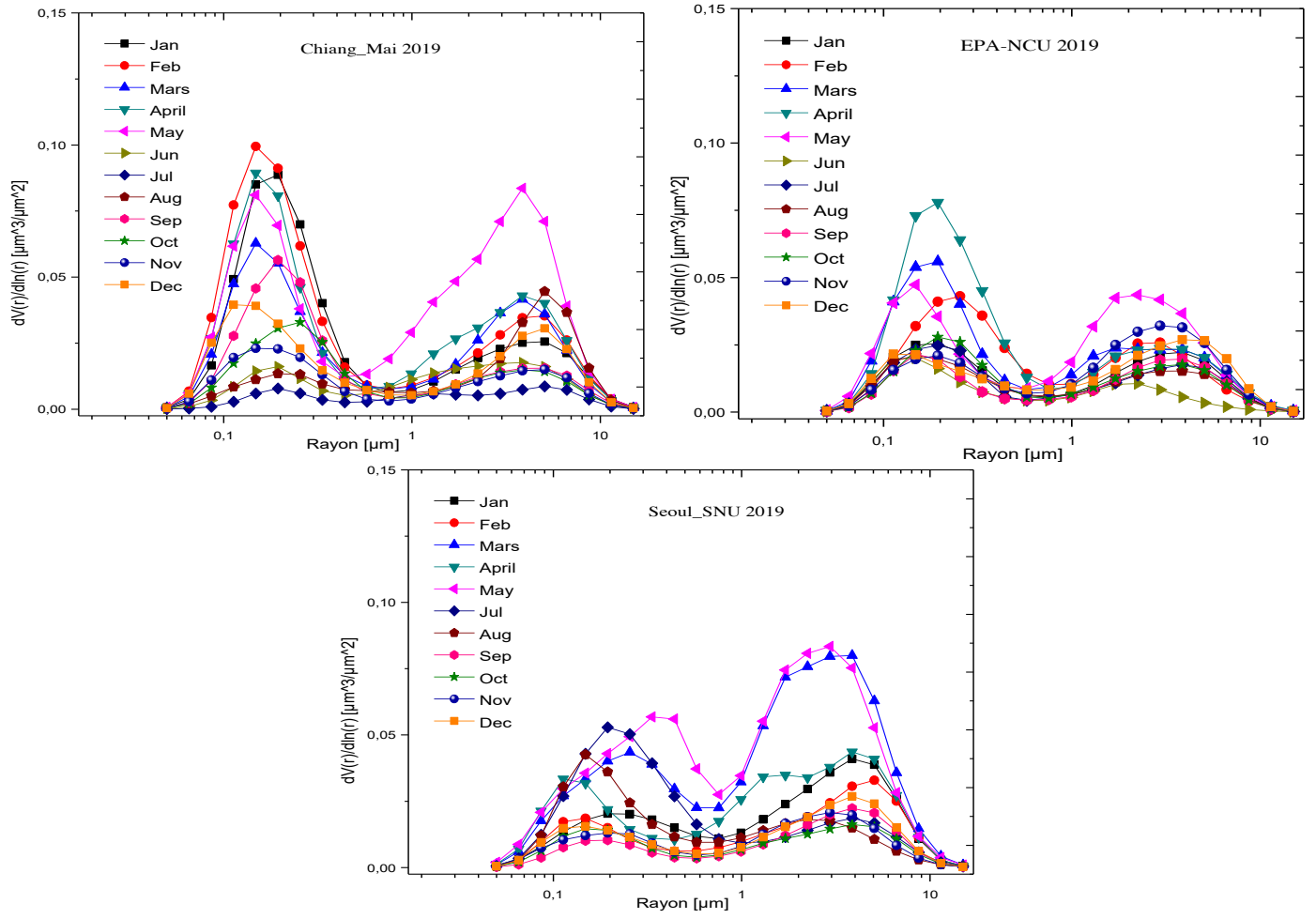

Fig. 2. Monthly average of aerosol particle size distributions
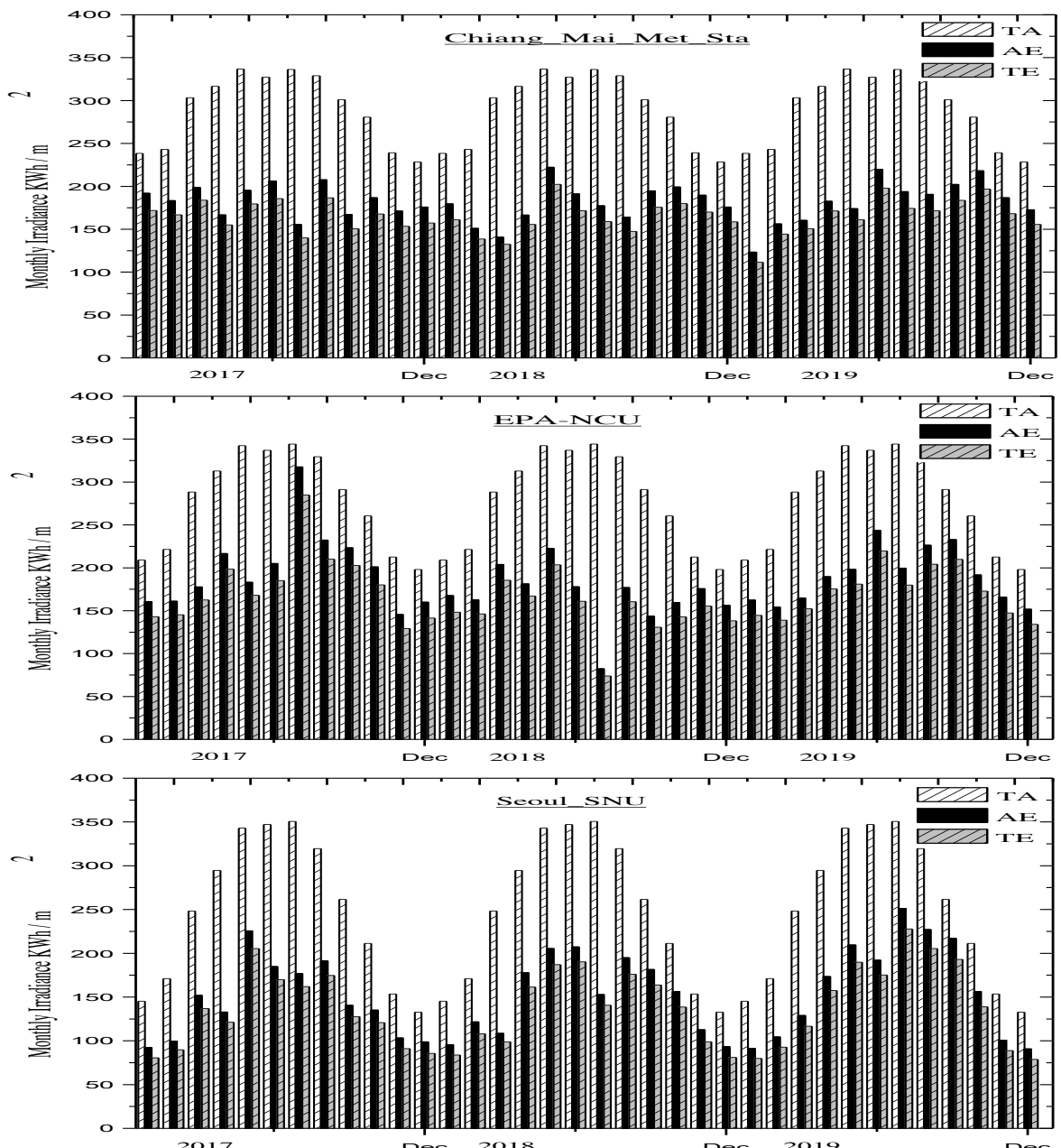

Fig. 3. Monthly solar irradiance during three years at top of atmosphere (TA), with aerosol extinction (AE), and with total extinction (TE). 
Figure 3 represents the monthly solar irradiance without the atmosphere (TA), with aerosol extinction (AE), and with total extinction (TE) during three years. The attenuation of solar irradiance occurs in the same seasonal manner every year because the aerosol optical depth is of seasonal period and takes very large values when seasonal emissions of aerosols are ample. Spring and summer observe the maximum attenuation of solar irradiance by aerosols in Chiang Mai and EPA-NCU. In Seoul, attenuation by aerosols present a very important slight rise in spring.

Table 2. Annual average of attenuation of solar irradiance during three years by the atmosphere (TE) and by the aerosols (AE).

\begin{tabular}{lcc}
\hline & TE & AE \\
\hline Chiang_Mai_Met_Sta & $43,13 \pm 0,78$ & $37,33 \pm 0,78$ \\
EPA-NCU & $40,01 \pm 5,82$ & $33,48 \pm 6,43$ \\
Seoul SNU & $44,74 \pm 3,29$ & $38,59 \pm 3,86$ \\
\hline
\end{tabular}

The annual rate average of the attenuation of solar radiation by the total atmosphere and by aerosols during three years at the three sites show the high attenuation by aerosols. The aerosol contributions seem relatively lower at EPA-NCU (Table 2).

\section{Conclusions}

The exploitation of solar energy requires accurate knowledge of the optical properties of the atmospheric components and the composition that vary from site to another. The three years analysis of three sites, localized in East Asia using AERONET database allow the determination of the solar irradiance attenuation by aerosols.

The monthly series within three years of AOD shows that the aerosols at each site are emitted almost periodically with varying values. AODs increase in spring due to the seasonal emission of aerosols from the biomass combustions. Fine modes around $0.15 \mu \mathrm{m}$ with the maximum volume concentration of $0.1 \mu \mathrm{m}^{3} / \mu \mathrm{m}^{2}$ dominate in February in Chiang Mai and EPA-NCU. EPA-NCU registers $0.08 \mu \mathrm{m}^{3} / \mu \mathrm{m}^{2}$ in April corresponding to fine mode radius near $0.19 \mu \mathrm{m}$.

The aerosol optical depth determines the solar irradiance attenuation by the total atmosphere. The large seasonal aerosol emissions, makes the total attenuation of solar radiation by the atmosphere very large; $40.01 \pm$ $5.82 \%$ in EPA-NCU, $43.13 \pm 0.78 \%$ in Chiang Mai and $44.74 \pm 3.29 \%$ in Seoul

The authors want to thank AERONET's IPs: Sang-Woo Kim, Neng-Huei and Serm Janjai.

\section{References}

1. Gueymard CA. A reevaluation of the solar constant based on a 42- year total solar irradiance time series and a reconciliation of spaceborne observations. Sol Energy 168(2018):2-9. (2018).
2. Diouri M. Atmosphère et climat, volume1, Université Mohamed Premier. Oujda, Maroc. (2018).

3. Ben-tayeb A, Diouri M, Meziane R Steli H. Solar radiation attenuation by aerosol: application to solar farms. Air Qual Atmos Health. 13(2), 259-269 (2020). doi:10.1007/s11869-020-00790-1

4. Son, J., Jeong, S., Park, H., \& Park, C. E. (2020). The effect of particulate matter on solar photovoltaic power generation over the Republic of Korea. Environmental Research Letters, 15(8), 084004. doi.org/10.1088/1748-9326/ab905b

5. Tahiri A, Diouri M, Steli H, Marsli I, Meziane R, Ben-tayeb A. Desert aerosol optical properties in Morocco. Environ Sci Hikari Ltd 4:63-78 (2016). doi.org/10.12988/es.2016.631

6. Barkani J, Tahiri A, Diouri M. Optical properties of desert aerosol -II. J Mater Environ Sci 9(10): 29042912 (2018).

7. Tahiri A, Diouri M, Barkani J. Optical properties of desert aerosol- I. J Mater Environ Sci 9(10):28702883 (2018).

8. Meziane R, Diouri M, Ben-tayeb A. Optical aerosol properties of megacities: inland and coastal cities comparison. Air Qual Atmos Health. 13(1), 25-33 (2019). doi.org/10.1007/s11869-019-00769-7

9. Diouri M, Hoyningen-HueneWV, Zarrouk T, Dinter T, Kokhanovsky A, Burrows JP. Determination of aerosol particle size distribution for mineral dust during the SAMUM campaign. European Aerosol Conference, Karlsruhe Abstract T052A16 (2009).

10. Steli H, Marsli I, Diouri M, Tahiri A. Aerosol and Cloud Optical Depths (AOD and COD) in the Equatorial Area. Environ Sci Hikari Ltd Vol. 4, 2016, no. $1, \quad 39 \quad-\quad 51 \quad$ (2016). dx.doi.org/10.12988/es.2016.51217

11. Steli H, Diouri M, Marsli I, Meziane R. Aerosol PSD and occurrence frequencies of clouds in the equatorial area. JMES,Volume 8, Issue 2, Page 648656 (2017).

12. Lee, K.H.; Kim, Y.J. Satellite remote sensing of Asian aerosols: A case study of clean, polluted, and Asian dust storm days. Atmos. Meas. Tech. 3, 17711784 (2010).

13. Kim, S. W., Yoon, S. C., Kim, J., \& Kim, S. Y. Seasonal and monthly variations of columnar aerosol optical properties over east Asia determined from multi-year MODIS, LIDAR, and AERONET Sun/sky radiometer measurements. Atmospheric Environment, 41(8), 1634-1651. (2007). doi.org/10.1016/j.atmosenv.2006.10.044

14. Kim, D. H., Sohn, B. J., Nakajima, T., Takamura, T., Takemura, T., Choi, B. C., \& Yoon, S. C. Aerosol optical properties over East Asia determined from ground-based sky radiation measurements. Journal of Geophysical Research: Atmospheres, 109(D2) (2004). doi.org/10.1029/2003JD003387

15. He, B., Bao, Q., Li, J., Wu, G., Liu, Y., Wang, X., \& Sun, Z. Influences of external forcing changes on the 
summer cooling trend over East Asia. Climatic change, 117(4), 829-841 (2013). doi.org/10.1007/s10584-012-0592-4

16. Diouri M, Sanda IS. Deduction of particle size distribution from aerosol optical depth CLEOPATRE I code. J Aerosol Sci 28(p):459 (1997).

17. Diouri M, El Hitmy M, Sanda IS, Jaenicke R, Kulzer $\mathrm{S}$, Leiterer U, Schutz L, Schultz KH. Indirect determination of particle size distribution using a sunphotometer at Lidenberg (Germany) and Oujda (Morocco). J Aerosol Sci 28(p):401 (1997)

18. Aerosol

ROboticNETwork, http://aeronet.gsfc.nasa.gov.

19. Pani, S. K., Lin, N. H., Chantara, S., Wang, S. H., Khamkaew, C., Prapamontol, T., \& Janjai, S. Radiative response of biomass-burning aerosols over an urban atmosphere in northern peninsular Southeast Asia. Science of The Total Environment, 633, 892-911 (2018). doi.org/10.1016/j.scitotenv.2018.03.204

20. Wang, S. H., Welton, E. J., Holben, B. N., Tsay, S. C., Lin, N. H., Giles, D., ... \& Chen, W. N. Vertical distribution and columnar optical properties of springtime biomass-burning aerosols over Northern Indochina during 2014 7-SEAS campaign. Aerosol and Air Quality Research, 15(5), 2037-2050 (2015). doi: 10.4209/aaqr.2015.05.0310

21. Park, S. S., Kim, S. W., Song, C. K., Park, J. U., \& Bae, K. H. Spatio-Temporal Variability of Aerosol Optical Depth, Total Ozone and NO2 Over East Asia: Strategy for the Validation to the GEMS Scientific Products. Remote Sensing, 12(14), 2256 (2020). doi.org/10.3390/rs12142256

22. Huang, K., Fu, J. S., Lin, N. H., Wang, S. H., Dong, X., \& Wang, G. Superposition of Gobi Dust and Southeast Asian Biomass Burning: The Effect of Multisource Long-Range Transport on Aerosol Optical Properties and Regional Meteorology Modification. Journal of Geophysical Research: Atmospheres, 124(16), 9464-9483 (2019). doi.org/10.1029/2018JD030241

23. Iqbal M. An introduction to solar radiation. Academic Press, Toronto (1983). 